\title{
Cellulose Microfibrils Filler Contributes to Thermal Stability and Morphology of Bioplastics from Sorghum-Based
}

\author{
Y Darni ${ }^{1}$ N I Hanifah ${ }^{1}$ H Utami $^{1}$ L Lismeri $^{1}$ M Hanif $^{1, *}$ \\ ${ }^{1}$ Department of Chemical Engineering, Universitas Lampung, Jl. S. Brodjonegoro No.1 Bandar Lampung, Indonesia \\ *Corresponding author. Email: muhammad.hanif@eng.unila.ac.id
}

\begin{abstract}
This research aimed to examine the effect of cellulose microfibrils (CMF) as a filler to thermal characteristics and morphology of bioplastic. Sorghum starch and chitosan, of which 63 micron particle size, were varied by starch to chitosan ratio $(\mathrm{g} / \mathrm{g})$ of 10:0; 9.5:0.5; 8.5:1.5; 7.5:2.5; 6,5:3.5; and 5.5:4.5 respectively. About $1 \mathrm{gr}(10 \%$ on a weight basis) of glycerol, as a plasticizer, was appended to the mixture. The addition of CMF was done to the mixture, and its concentration was varied $0,1,2$, and $3 \%(\mathrm{w} / \mathrm{w})$. The combination of $8.5 \mathrm{~g}$ sorghum starch and $1.5 \mathrm{~g}$ chitosan gave the best results. It revealed the enhance of the thermal characteristic of bioplastic due to the increase of the filler - this phenomenon expressed by glass transition, crystallinity, and melting temperature of bioplastic. The SEM analysis on the morphology structure of the bioplastic surface showed that the addition of the filler will contribute to dense of bioplastic structure.
\end{abstract}

Keywords: Bioplastic, Sorghum, Cellulose Microfibrils, Thermal Characteristic, Chitosan

\section{INTRODUCTION}

Plastics derived from petroleum can be one of the materials used the most to facilitate human life because of its strength and flexibility, and economically used. However, the use of such plastics in daily life can increase environmental problems due to its low level of degradability. The plastics may be difficult to degrade by decomposing bacteria, resulting in an accumulation of plastic waste in the environment. In order to minimize the negative impact on the environment; therefore, the innovation to make plastic can be biologically degraded is mandatory. One effort to be realized is the making of biodegradable plastics or bio-based plastics that match the characteristics of petroleum-based plastics [1].

Bioplastics synthesize by using renewable organic resources and easily to biodegrade [2]. These material feedstocks consist of natural polymers, such as polysaccharides and proteins [3]. Sorghum starch is one of the natural polysaccharides potentially used for this purpose. It is derived from the Sorghum plant (Sorghum bicolor L.), a type of cereal plant which has promisingly to develop and cultivate, especially in dry areas with $80.42 \%$ starch content [4]. However, starch-based bioplastics have the disadvantages of the low mechanical properties and the high rate of water absorption. Therefore, the presence of additives is needed in order to enhance its properties. The addition of chitosan in the starch-based bioplastics can reduce the rate of water absorption due to its hydrophobicity [1]. The mechanical properties can also be improved by means of a filler [5]. The filler has a function that occupies the cavity between bioplastic constituents that can make it denser. The difference in the size of the filler can also influence its density. The smaller the size of the filler applied has made bioplastic more dense due to its surface homogeneity enhanced [2].

This study examined the influence of microfibril cellulose presented in the ingredients to the morphological and thermal properties of the bioplastic produced. 


\section{MATERIALS AND METHODS}

\subsection{Materials}

The main ingredients in bioplastic synthesis were sorghum starch and glycerol, and as a filler, microfibril cellulose used, extracted from sorghum stem powder. Sorghum starch and sorghum stem were retrieved from BPTP Lampung. The chemicals used along bioplastic preparation are potassium hydroxide $(\mathrm{KOH})$, hydrogen peroxide $(\mathrm{H} 2 \mathrm{O} 2)$, acetic acid $(\mathrm{CH} 3 \mathrm{COOH})$, and distilled water.

\subsection{Synthesis of Cellulose Microfibrils (CMF)}

The processing of CMF from the sorghum stem was done by a semi-mechanical method [5]. Sorghum stem powder, 100 mesh in size, was weighed to about $10 \mathrm{~g}$, experienced delignification by means $4 \% \mathrm{KOH}$ solution at $80{ }^{\circ} \mathrm{C}$ for one hour. After filtration, the solid filtrate underwent a bleaching process by $6 \% \mathrm{H} 2 \mathrm{O} 2$ solution at $70{ }^{\circ} \mathrm{C}$ for one hour. Again, delignification performed by a $4 \% \mathrm{KOH}$ solution with the same procedure. Finally, the filtrate was rinsed by distilled water to neutralize the basicity and dried into an oven at $100{ }^{\circ} \mathrm{C}$ for three hours. The dried extract of cellulose reduced its size by a dish mill for 90 minutes and then store in a zip bag as CMF feedstocks.

\subsection{Synthesis of Bioplastics}

The bioplastic synthesis was done according to Ban et al., procedure with some modifications [6]. Starch and chitosan were made in $10 \mathrm{~g}$ total by weight (on a dry basis) with some variation on starch to chitosan ratios (w/w), typically 10:0, 9.5:0.5, 8.5:1.5, 7.5:2.5, 6.5:3.5, and 5.5:4,5. The chitosan needed to solve in acetic acid to obtain a $20 \%$ solution. About $10 \%$ of glycerol (w/w) as a plasticizer was also prepared. The addition of CMF as a filler was done, and its presence varied $0,1,2$, and $3 \%(\mathrm{w} / \mathrm{w})$ based on $10 \mathrm{~g}$ total weight. The bioplastic preparation was conducted by mixing sorghum starch, chitosan, glycerol, and distilled water and heating at $95^{\circ} \mathrm{C}$ while stirring at $375 \mathrm{rpm}$ and 35 minutes. The bioplastic solution removed from the hot plate and cooled down until its temperature dropped to $35^{\circ} \mathrm{C}$. The solution then poured into a mold and dried in an oven at $60{ }^{\circ} \mathrm{C}$ for 10 hours.

The bioplastic sheets were analyzed thermally by differential scanning calorimetry, and its surface morphology was observed using scanning electron micrograph (ZEIZZ EVO MA 10).

\section{RESULTS AND DISCUSSION}

\subsection{The Morphology of CMF}

The morphology of CMF was also examined by scanning electron microscopy, and the result is shown in Figure 1. It was informed that the CMF filler has 2-8 $\mu \mathrm{m}$ diameter. The values were smaller when compared to the previous study [7], which was $63 \mu \mathrm{m}$. These results might be due to the difference in mechanical treatment used. Mechanical treatment by the dish mill has split the CMF into smaller diameter as it observed. Furthermore, chemical treatment, alkaline peroxide, has proven to reduce lignin and hemicellulose contents in sorghum stem powder to about 81 to $86 \%$, and therefore affected the quality of extracted CMF [5]. As a result, the cellulose content in the CMF after treatment significantly increased to become $50 \%$.

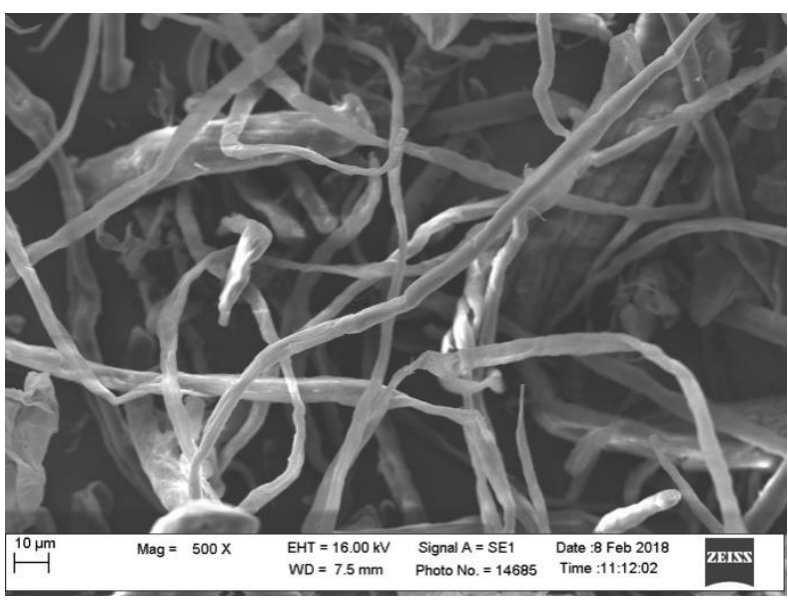

Figure 1 The morphology of CMF on 500x magnification after chemical and mechanical treatments.

\subsection{The Thermal Characteristics of Bioplastics}

The result of DSC analysis for a polymer material provided information of thermal parameters, namely as glass transition point ( $\mathrm{Tg}$ ), crystallization point (Tc), and melting point $(\mathrm{Tm})$. The glass transition point $(\mathrm{Tg})$ is the temperature at which a material changes from a glassy to rubbery. The crystallization temperature (Tc) is the temperature when the polymer in a crystalline state. Meanwhile, the melting point (Tm) is the parameter when the polymer starts to melt into a liquid state [8]. 
DSC analysis performed in one through heating process. The trendline will show transition points from $\mathrm{Tg}$, Tc, and Tm, respectively. The results of the analysis on bioplastics synthesized from $8.5 \mathrm{~g}$ sorghum starch, 1.5 g chitosan $10 \%$ glycerol as a plasticizer, and also CMF filler addition by $0,1,2$ and $3 \%$ by weight are shown in Figures 2, 3, 4, and 5. Overall, these thermal properties declined as CMF filler increased within this range. The reduction of $\mathrm{Tg}$ values might be due to the increase of the stiffness of bioplastic as CMF filler added. The increase in crystallinity corresponded to the interaction between bioplastic in the hydroxyl part at the end terminal of the bioplastic chain to form hydrogen bonds which can induce the bioplastic crystallization process, thereby increasing the bioplastic crystallinity. A decrease in Tm was due to the positive charge of the hydrogen atoms in the $\mathrm{CH}$ - group to the negatively charged oxygen group in the weakened $\mathrm{C}=\mathrm{O}$ group. Weak hydrogen bonds have lessen the melting point [8].

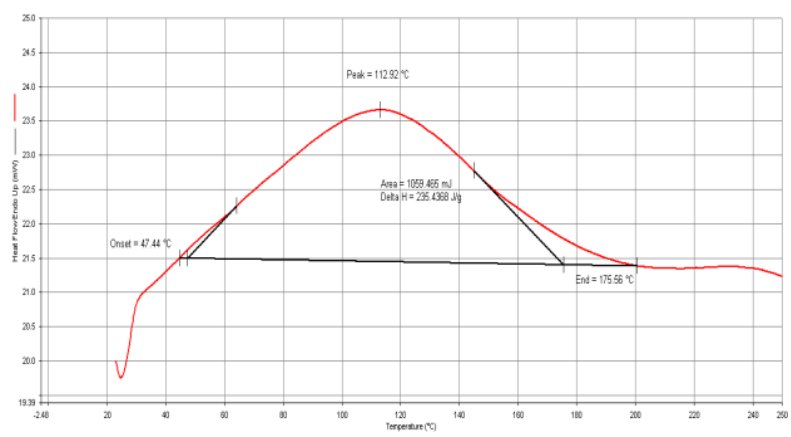

Figure 1 DSC results of bioplastics made from $8.5 \mathrm{~g}$ sorghum starch, $1.5 \mathrm{~g}$ chitosan, and $10 \%$ glycerol

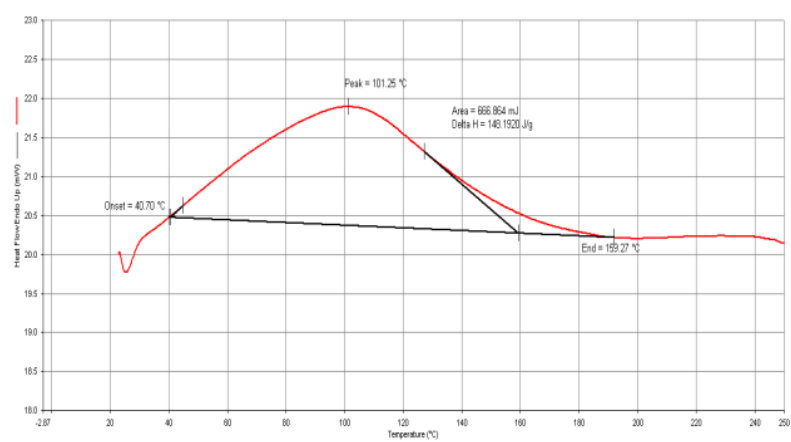

Figure 2 DSC results of bioplastics made from $8.5 \mathrm{~g}$ sorghum starch, $1.5 \mathrm{~g}$ chitosan, $10 \%$ glycerol, and $1 \%$ CMF filler

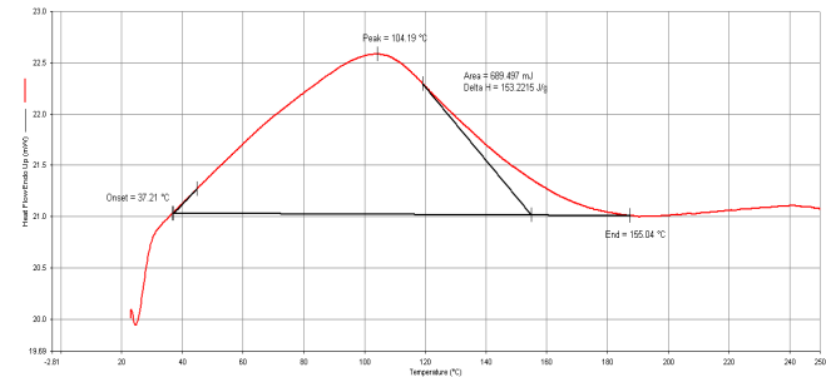

Figure 3 DSC results of bioplastics made from $8.5 \mathrm{~g}$ sorghum starch, $1.5 \mathrm{~g}$ chitosan, $10 \%$ glycerol, and $2 \%$ CMF filler

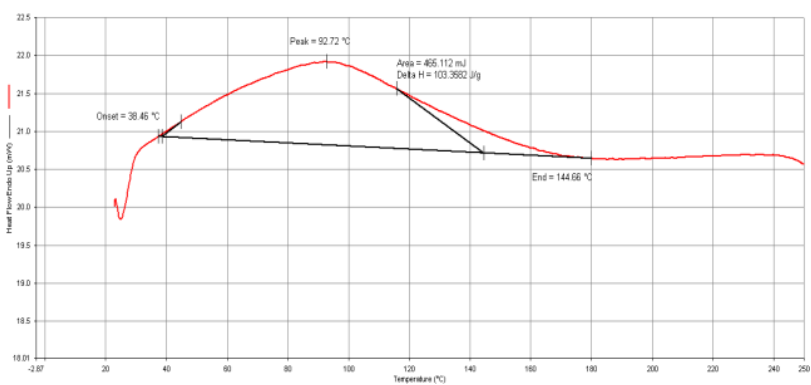

Figure 5 DSC results of bioplastics made from $8.5 \mathrm{~g}$ sorghum starch, $1.5 \mathrm{~g}$ chitosan, $10 \%$ glycerol, and $3 \%$ CMF filler

\subsection{The Morphology of Bioplastics}

Analysis of SEM has observed from bioplastics by combination $8.5 \mathrm{~g}$ sorghum starch, $1.5 \mathrm{~g}$ chitosan and $10 \%$ glycerol as a plasticizer, and also CMF filler addition by $0,1,2$ and $3 \%$ by weight. The morphology of the surface is shown in Figure 6. It can be seen that the more CMF filler added, the higher of the homogeneity of bioplastic resulted. Also, this additive can also increase the smoothness of the matrix. It was because the trapped CMF will fill the empty cavity on the bioplastic surface that contributed to improving the bioplastic density [2]. 


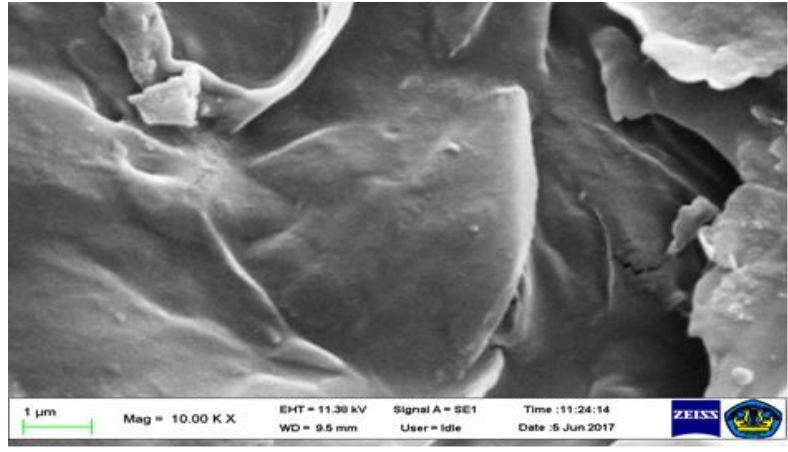

(a)

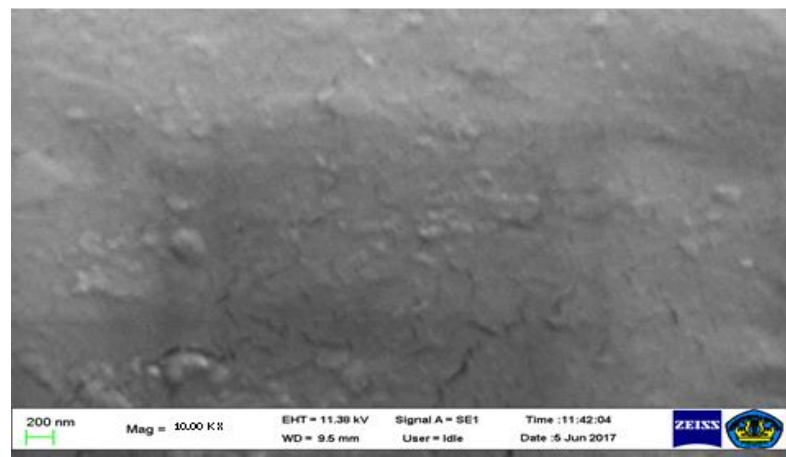

(b)

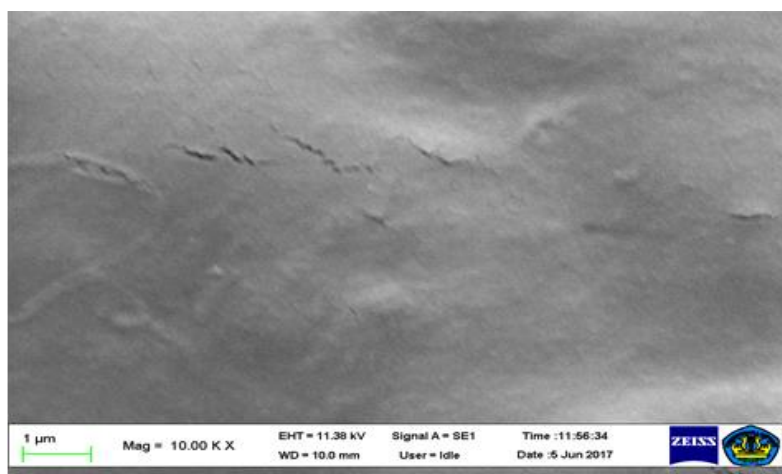

(c)

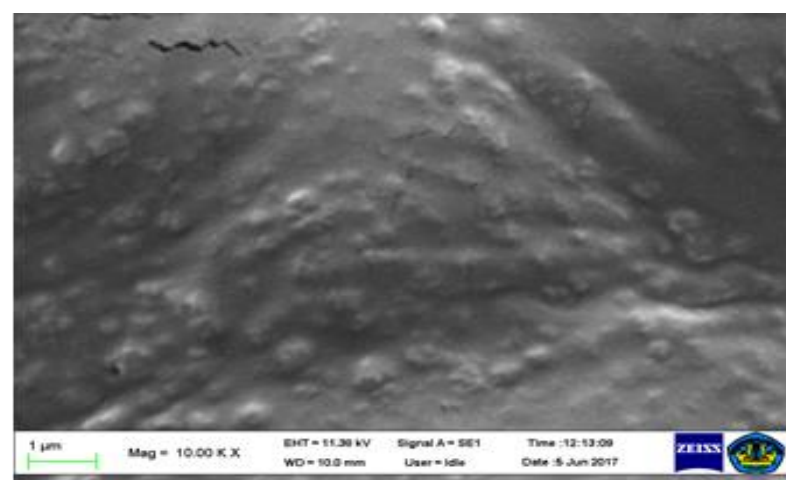

(d)

Figure 6 SEM images of bioplastics comprising of $8.5 \mathrm{~g}$ sorghum starch and $1.5 \mathrm{~g}$ chitosan on various CMF filler concentrations: (a) without filler addition, (b) $1 \%$ filler addition, (c) $2 \%$ filler addition, and (d) $3 \%$ filler addition.

\section{CONCLUSION}

The addition of CMF as an additive filler in the manufacture of sorghum-based bioplastics influenced the morphology and thermal characteristics of the bio composite products. Increasing of filler concentration up to $3 \%$ has been able to reduce the glass transition point ( $\mathrm{Tg}$ ), the crystallization point (Tc), the melting point (Tm). Also, the addition of filler in the mixture can improve the homogeneity and surface morphology of the resulting bioplastics.

\section{ACKNOWLEDGMENTS}

The authors give the appreciation to the Ministry of Research, Technology and Higher Education which has funded this research through the DPRM Dikti (PPT) Applied Product research grant 2017 based on contract number 071/SP2H/LT/DPRM/IV/2017. We also acknowledge to the UPT LTSIT Universitas Lampung for facilitating the analysis of this study.

\section{REFERENCES}

[1] Elpita F., Darni Y., 2015, Pros. Sem. Nas. Sains. Tek VI (Bandar Lampung: LPPM Unila) p 599-609

[2] Pilla S., 2011, Handbook of Bioplastics and Biocomposites Engineering Applications (New Jersey: John Wiley \& Sons)

[3] Babu R P, O'Connor K., Seeram R., 2013, Prog. Biomater 21-16

[4] Suarni, 2004, J. Litbang Pertanian 23145-51

[5] Wicaksono R., 2013, Isolasi Nano serat Selulosa dari Ampas Tapioka dan Aplikasinya sebagai Bahan Pengisi Film Tapioka (Bogor: Institut Pertanian Bogor).

[6] Ban W, Song J, Argyropoulos D S, Lucia LA., 2006, Ind. Eng. Chem. Res 45 627-33

[7] Darni Y, Darmansyah, Lismeri L, Binur, 2015, Integrated Sci-Tech: The Interdisciplinary Research Approach vol 1 ed A Ulvan and I Sukmana (Bandar Lampung: UPT. Perpustakaan Universitas Lampung) chapter 1 pp 6-12

[8] Ashok A., Rejesh C R., 2017, J. Polym. Compos 515-24 